\title{
Accurate method for measuring arterial pulse wave velocity by cardiovascular magnetic resonance
}

\author{
El-Sayed Ibrahim \\ From 15th Annual SCMR Scientific Sessions \\ Orlando, FL, USA. 2-5 February 2012
}

\begin{abstract}
Summary
A modified version of the flow-area (QA) method for measuring pulse wave velocity (PWV) from CMR images is introduced. The new 'flow-time-area' (QTA) method is more robust to errors in area measurements than the QA method, which is mathematically proved and demonstrated in pulmonary hypertension study. PWV was correlated to measurements from catheterization, echo, and CMR. The effect of image resolution, inter-, and intra-observer variabilities were studied. The results showed superiority of the QTA method over QA method.
\end{abstract}

\section{Background}

The flow-area (QA) method has potential importance for measuring pulse wave velocity (PWV) from CMR images, especially in the pulmonary artery (PA). Nevertheless, the QA method is highly affected by errors in area measurements. In this work, we introduce the 'flow-time-area'(QTA) method, a modified version of QA, which has benign behavior to area measurements inaccuracies.

\section{Methods}

In QTA, area and flow changes are calculated separately w.r.t. time, from which PWV is calculated by dividing the two slopes. The following sections show that QTA is more accurate than than QA.

\section{Mathematical proof}

In QA, flow measurements, $\mathrm{q}$, are related to area measurements, a, by linear least-squares fit: $q=u a+v$, where $\mathrm{PWV}_{\mathrm{QA}}=\mathrm{u}$. By solving the normal equation $\Rightarrow \mathrm{PWV}_{\mathrm{QA}}=$

Department of Radiology, University of Florida, Jacksonville, FL, USA $\left(\mathrm{m} \sum \mathrm{a}_{\mathrm{i}} \mathrm{q}_{\mathrm{i}}-\sum \mathrm{a}_{\mathrm{i}} \sum \mathrm{q}_{\mathrm{i}}\right) /\left(\mathrm{m} \sum\left(\mathrm{a}_{\mathrm{i}}\right)^{2}-\left(\sum \mathrm{a}_{\mathrm{i}}\right)^{2}\right)$, where $\mathrm{m}=$ \#measurements. In QTA, two lines are formed: $q=u_{1} t+v_{1}$ and $\mathrm{a}=\mathrm{u}_{2} \mathrm{t}+\mathrm{v}_{2}$, from which $\Rightarrow \mathrm{PWV}_{\text {QTA }}=\left(\mathrm{m} \sum \mathrm{t}_{\mathrm{i}} \mathrm{q}_{\mathrm{i}}-\sum \mathrm{t}_{\mathrm{i}} \sum \mathrm{q}_{\mathrm{i}}\right) /$ $\left(\mathrm{m} \sum \mathrm{t}_{\mathrm{i}} \mathrm{a}_{\mathrm{i}}-\sum \mathrm{t}_{\mathrm{i}} \sum \mathrm{a}_{\mathrm{i}}\right)$. Under perfect linear relationship between $\mathrm{q}$ and $\mathrm{a}, \mathrm{PWV}_{\mathrm{QA}}=\mathrm{PWV} \mathrm{V}_{\mathrm{QTA}}=\mathrm{u}$. We analyze the case of positive error in area measurement $(\Delta \mathrm{a})$ at point $j$. $j$ is assumed $>m / 2$, which reduces PWV and the accuracy measure $\mathrm{M}=\mathrm{PWV} / \triangle \mathrm{PWV}-1$, where $\triangle \mathrm{PWV}$ is the difference between exact and measured PWV. For zero measurement error, $M \rightarrow \infty$. By mathematical manipulation, $\mathrm{M}_{\mathrm{QA}}=\left(\mathrm{N}_{1}+\mathrm{N}_{2}\right) /\left(\mathrm{D}_{1}+\mathrm{D}_{2}\right)$ and $\mathrm{M}_{\mathrm{QTA}}=\mathrm{N}_{1} / \mathrm{D}_{1}$, where $\mathrm{N}_{1}=\mathrm{u}_{2}\left(\mathrm{~m} \sum\left(\mathrm{t}_{\mathrm{i}}\right)^{2}-\left(\sum \mathrm{t}_{\mathrm{i}}\right)^{2}\right), \mathrm{N}_{2}=\mathrm{D}_{1}=\left(\mathrm{mt}_{\mathrm{j}}-\sum \mathrm{t}_{\mathrm{i}}\right) \Delta \mathrm{a}$, and $\mathrm{D}_{2}=(\mathrm{m}-1)$ $(\Delta \mathrm{a})^{2} / \mathrm{u}_{2}$. It can be shown that $\mathrm{N}_{1} \mathrm{D}_{2}-\mathrm{N}_{2} \mathrm{D}_{1}=\left(\mathrm{t}_{\mathrm{i}}-\mathrm{t}_{\mathrm{k}}\right)^{2} \geq 0$ (summation over $\mathrm{i}>\mathrm{k} ; \mathrm{i}, \mathrm{k} \neq \mathrm{j}$ ), which proves that $\mathrm{M}_{\mathrm{QA}} \leq \mathrm{M}_{\mathrm{QTA}}$.

\section{Application}

50 human subjects (25 PA hypertension (PAH) and 25 volunteers) were scanned on Siemens 3T scanner. Two sets of velocity-encoded images were acquired with resolutions $0.7 \mathrm{~mm}$ and $1.4 \mathrm{~mm}$ (Fig. 1). PA boundary was semi-automatically determined by two observers. PWV was calculated by QTA and QA. The measurements were compared using t-test. Normalized least-squares errors were calculated. Correlation analysis was conducted between PWV and mean PA pressure (mPAP), pulmonary vascular-resistance (PVR), and cardiac-index (CI). Bland-Altman analysis was conducted to measure inter- and intra-observer variabilities.

\section{Results}

$\mathrm{PWV}_{\mathrm{QTA}}$ and PWV $\mathrm{QA}_{\mathrm{QA}}$ showed significant differences in $\mathrm{PAH}(\mathrm{p}<.005)$, and less significant in volunteers $(\mathrm{p}=.01)$. The following results are for PAH: Normalized fittingerrors were $0.16 / 0.31$ for QTA/QA. Correlation coefficients 


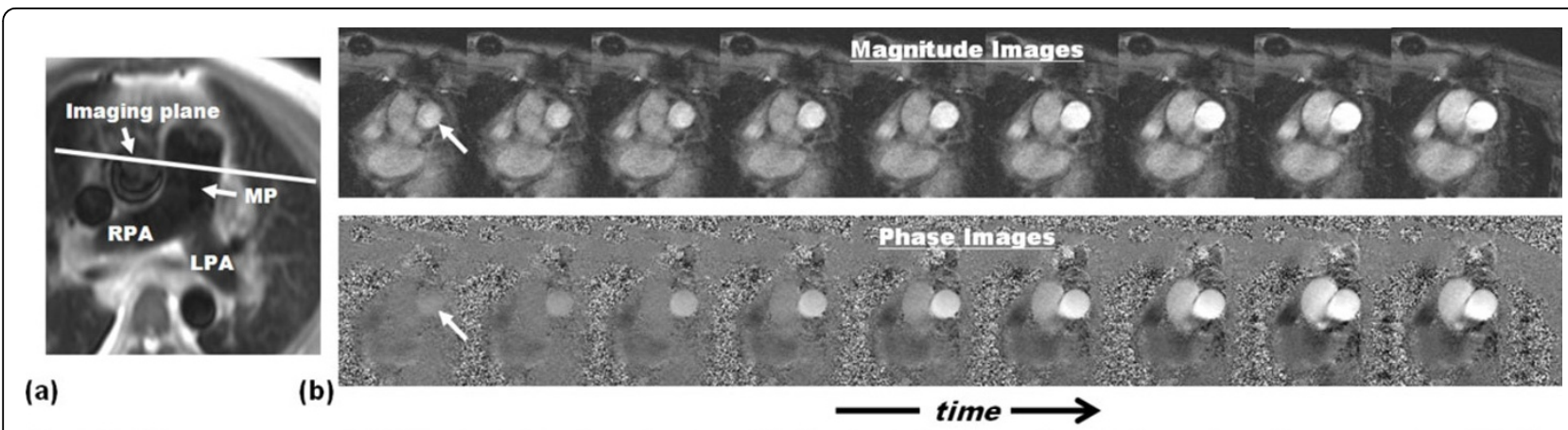

Fig 1. PWV measurement. (a) The imaging plane is prescribed perpendicular to flow in the main pulmonary artery (MPA). (b) Succession of magnitude (top) and velocity-encoded phase (bottom) images showing the MPA cross section during early systole. The images show continuous increase in the artery cross sectional area (top) and flow (bottom).

Figure 1
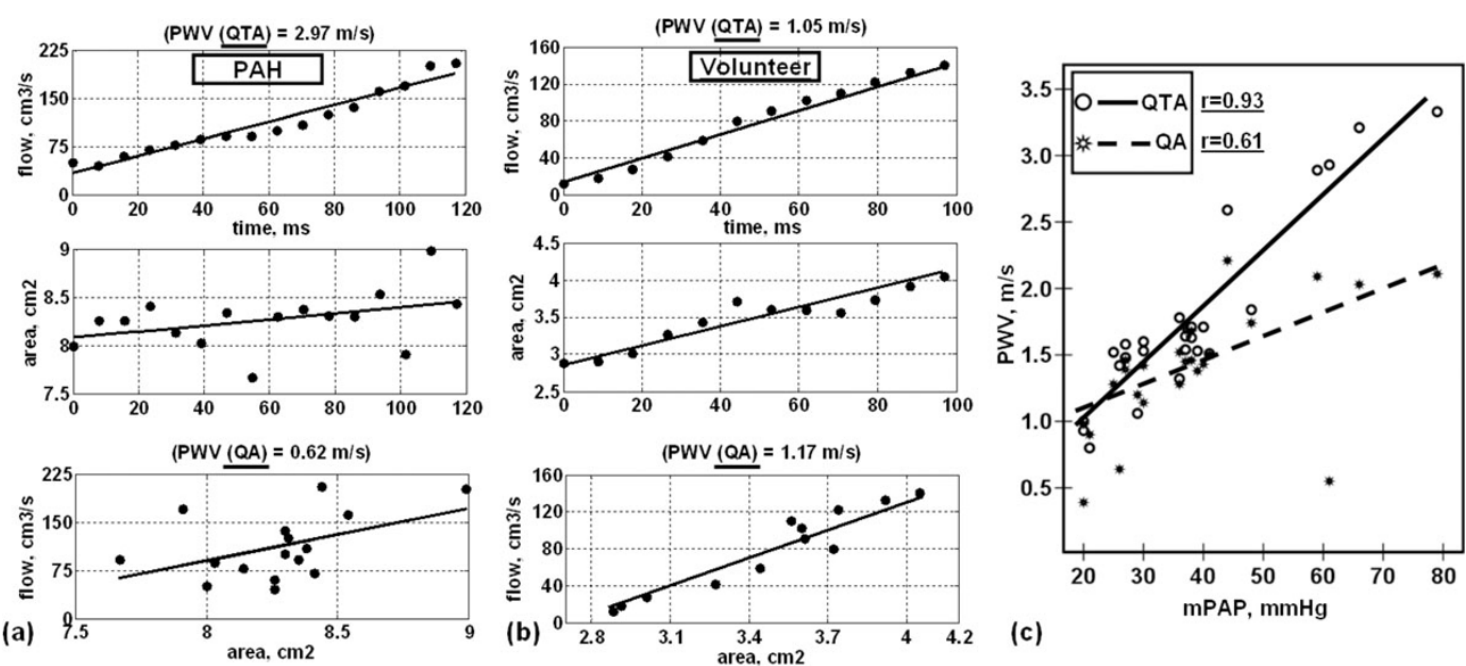

Fig 2. QTA and QA methods for measuring pulmonary artery (PA) PWV $n$ PA hypertension (PAH) and volunteers. (a) Results in PAH (QA: lower; QTA upper panels) show large differences between QA and QTA measurements due to large errors in area measurements (secondary to slight vessel wall extension). (b) Results in volunteers show little differences between the two methods due to artery compliance. (c) Correlations and regression lines between mean PA pressure (mPAP) versus PWV_QTA and PWV_QA in PAH, which show significant differences between the two methods, especially in severe PAH conditions.

Figure 2

between PWV versus mPAP, PVR, and CI were 0.93/0.61, $0.86 / 0.65,-0.71 /-0.62$ for QTA/QA. Standard deviations of differences between high- and low-resolution measurements were $0.19 / 0.41 \mathrm{~m} / \mathrm{s}$ for QTA/QA. Correlation coefficients between low-resolution PWV and mPAP were 0.87/0.4 for QTA/QA. Bland-Altman showed minimal inter- and intra-observer variabilities.

\section{Conclusions}

The QTA method is more accurate than QA, because area measurement errors are not propagated to flow. The improved QTA accuracy is imperative when changes in artery cross-sectional area are minimal(e.g. $\mathrm{PAH})$, when spatial resolution is low, or automatic vessel segmentation is implemented. Thus, QTA should be adopted for accurate PWV estimates.

\section{Funding}

James \& Esther King Grant \# 09KN-03-23138.

Published: 1 February 2012

doi:10.1186/1532-429X-14-S1-012

Cite this article as: Ibrahim: Accurate method for measuring arterial pulse wave velocity by cardiovascular magnetic resonance. Journal of Cardiovascular Magnetic Resonance 2012 14(Suppl 1):O12. 